\title{
REVISIÓN/REVIEW
}

Recibido: 24/09/2013-----Aceptado: 21/10/2013-----Publicado: 15/03/2014

\section{PRINCIPIOS Y CARACTERES NORMATIVOS DE LOS DERECHOS HUMANOS}

Cristina Fuertes-Planas Aleix ${ }^{\mathbf{1}}$ : Universidad Complutense de Madrid. España. cfuertes@ucm.es

\section{RESUMEN}

Los derechos humanos se rigen por cinco principios normativos: la libertad, la igualdad, la dignidad, así como la Justicia y el bien común. Los dos primeros son concebidos a título universal y la mayor parte de los tratadistas occidentales han considerado la libertad como un valor supremo. Libertad e igualdad necesitan ser ponderados ya que, si predomina en exceso la libertad puede disminuir la igualdad y si, por el contrario, la balanza se inclina por la igualdad, puede ser a costa de la libertad (liberalismo sin limitaciones y socialismo autoritario). La dignidad es un principio aglutinador que hace referencia a la consideración del ser humano con una naturaleza propia y singular. La Justicia y el bien común aluden al aspecto social del hombre. Como posibles características clásicas de los derechos humanos encontramos la universalidad, su carácter absoluto y su carácter inalienable. En este estudio acometemos estos caracteres, sus limitaciones y consideraciones realizadas por la doctrina más relevante.

PALABRAS CLAVE: Libertad - Igualdad - Dignidad- Justicia - Bien común.

\footnotetext{
${ }^{1}$ Cristina Fuertes-Planas Aleix: Universidad Complutense de Madrid. Facultad de Ciencias de la Información. España.

Correo: cfuertes@ucm.es
} 


\title{
PRINCIPLES AND CHARACTERS NORMATIVES OF HUMAN RIGHTS
}

\begin{abstract}
Civil rights are governed by five normative principles: freedom, equality and dignity, as well as justice and the common good. The first two are conceived on a universal scale, and the majority of western scholars have considered freedom as a supreme asset. Freedom and equality have to be weighed since if freedom prevails excessively, equality may be depleted. If, contrariwise, the scale is tipped toward equality, freedom may be reduced (limitless liberalism ant authoritarian socialism). Dignity is a bonding principle which engages the consideration of the human being with a unique nature all its own. Justice and the common good refer to a man's social facet. Within the possible classic characteristics of human rights we find universality, a character which is absolute and inalienable. In the present study, we engage these characters, their limitations, and considerations fulfilled by the most relevant doctrine.
\end{abstract}

KEYWORDS: Freedom - Equality - Dignity - Common good.

\section{PRINCIPIOS NORMATIVOS DE LOS DERECHOS HUMANOS}

Los valores que informan en mayor medida y contribuyen al despliegue de los diferentes derechos humanos son la dignidad, la libertad y la igualdad. Existen otros valores como la paz, la seguridad, o el pluralismo jurídico, pero estos, en última instancia, pueden reconducirse a los anteriores.

Los principios de libertad e igualdad han sido formulados, tanto en la Declaración de Derechos del Hombre y del Ciudadano, de 1789, en cuyo artículo $1^{\circ}$ se dice que "los hombres nacen y viven libres e iguales en derechos", como en la Declaración Universal de Derechos Humanos de 1948, cuando señala que "todos los seres humanos nacen libres e iguales en dignidad y derechos y, dotados como están de razón y conciencia, deben comportarse fraternalmente los unos con los otros." En consecuencia, libertad e igualdad son principios normativos básicos de los derechos humanos.

\subsection{El principio de libertad}

La libertad ha constituido el principio aglutinante de los restantes derechos, incluso identificándose, en muchas ocasiones, con los propios derechos humanos. En época reciente, HERBERT L. A. HART, quien realiza un estudio de los derechos naturales en el ámbito de la crítica a la tradición metafísica, reconoce como un solo derecho natural "el igual derecho de todos los hombres a ser libres".

La libertad puede ser natural, del hombre en la naturaleza, cuestión tratada por los autores pactistas, lo que ha llevado a preguntarse si los acontecimientos naturales son libres o están determinados, si la conducta humana es libre o está determinada y 
puede predecirse del mismo modo que los fenómenos naturales. Y en caso de no ser libre, si se incumple algún deber. En este sentido, I. KANT señaló que aunque pudiera preverse la conducta del hombre, seguiría siendo libre, ya que el hombre es un ser natural y también un ser moral. Su conducta es naturalmente necesaria y moralmente libre desde la perspectiva de la razón práctica. Para hacer uso de la razón es necesario el presupuesto de la libertad. La libertad excluye la necesidad.

La libertad natural se ha entendido en el iusnaturalismo moderno como la poseída por el hombre en el estado de naturaleza, al contrario de la libertad en la sociedad civil después de instituir el Estado y el Derecho.

La libertad en sentido jurídico significa el poder o facultad de obrar, que se fundamenta en la naturaleza del hombre para el cumplimiento de sus finalidades y es reconocida por el Derecho con ocasión de la regulación de las relaciones sociales. La idea de libertad es inescindible del Derecho, ya que éste limita la libertad existencial o natural. La libertad no es ni absoluta ni abstracta, como se entiende desde una postura liberalista. Requiere de la existencia de instituciones sociales y jurídicas, con la finalidad de conciliarla con el orden.

La libertad política es la libertad como autodeterminación (no se obedecen más normas que las autoimpuestas): la participación en la designación y control de los gobernantes y en la elaboración de las leyes.

La libertad material o real significa capacidad para actuar, es decir que las libertades negativas y políticas no tengan un carácter puramente abstracto o formal, sino que sean reales, por lo que el Estado debe intervenir activamente.

Ha existido una contraposición entre la libertad de los modernos (libertad negativa del liberalismo) y la libertad de los antiguos (libertad como participación en Grecia y Roma). La "libertad de los antiguos" difiere, por ello, de la de los modernos, como hizo notar ya BENJAMIN CONSTANT, a comienzos del siglo XIX. La libertad de los antiguos significa, según este autor, la participación de cada hombre libre en la libertad de interferencia del Estado en la vida del hombre, reconociendo al Estado como la comunidad más alta que comunica al hombre su dignidad como ser libre. No suponía una tutela del individuo frente al Estado, sino que implicaba una libertad como identificación con los valores éticos de la comunidad. La concepción de la libertad de los modernos, concebida como libertad negativa, y salvaguarda de la seguridad por parte del Estado, por lo que se establece un órgano representativo para delimitar la competencia y vigilar los gastos y la eficiencia del Estado. En el Estado liberal se posee el derecho a elegir los fideicomisarios, (y no la participación en el ejercicio de la soberanía, como en la antigüedad), y elegida también la judicatura independiente. Se cuenta así con una garantía suficiente para el "imperio de la ley" que satisfaga los intereses de las clases propietarias. B. CONSTANT consideraba que la única libertad posible en su época era la libertad negativa, incompatible con el concepto positivo de libertad (libertad de los antiguos). La concepción liberal de libertad supone separar la vida privada de la pública, el individuo del Estado. En la Ciudad-Estado el individuo se identificaba con el ciudadano, no existía tal contraposición entre lo privado y lo público 
y, en consecuencia, carecía de sentido establecer esferas privativas para la actuación del individuo.

Por otra parte, la libertad material (como capacidad) no interfiere con las anteriores libertades, sino con las condiciones para su ejercicio, aunque si la falta de capacidad es total, no cabe hablar de libertad.

\subsection{El principio de igualdad}

El principio de igualdad hace alusión a que todos los hombres poseen la misma naturaleza y dignidad. El Estado debe garantizar un mínimo de vida que le corresponde a su dignidad como ser humano. La igualdad se refiere a la obtención de seguridad económica, participación en las funciones públicas, igualdad de oportunidades y de acceso a la educación y la cultura. No es posible una igualdad efectiva social y económica, aunque es necesario suprimir condiciones favorables arbitrarias. En las diferentes etapas históricas ha tenido mayor relevancia, ya sea la libertad (individualismo y liberalismo), ya sea la igualdad (económica, social y política). La posibilidad de conflicto entre igualdad y libertad se puso de relieve en el siglo XIX por autores como A. de TOCQUEVILLE, BURKE o A. CÁNOVAS DEL CASTILLO y también por los neoliberales contemporáneos. En sentido opuesto, la posición autoritaria del socialismo considera que mientras no se consiga una sociedad plenamente igualitaria no tienen valor las libertades.

La igualdad puede ser de características, lo que supone un concepto relativo, ya que hace referencia a la comparación entre diversos seres. Supone la posibilidad de asignar una serie de características comunes, siendo éstas más numerosas que las divergentes. Este es el sentido de igualdad de la tradición iusnaturalista empirista anglosajona (HUME, HOBBES, LOCKE), que continúa H. L. A. HART, quien se refiere al "contenido mínimo de Derecho natural". Existe para este autor una igualdad aproximada de los seres humanos, de donde deriva la necesidad del Derecho y de la moral (sistema de abstenciones y concesiones mutuas) porque "aunque los hombres difieren entre sí en fuerza física, agilidad y aún más en capacidad intelectual", sin embargo "ningún individuo es más poderoso que los otros hasta tal punto que pueda, sin cooperación, dominarlos o sojuzgarlos, salvo durante un término muy breve". La igualdad de características es una cuestión de hecho.

Y existe la igualdad de trato, que es una noción prescriptiva, significa que los seres A y $B$ deben ser tratados del mismo modo (siempre o en determinadas circunstancias); lo que no es lo mismo que afirmar que son iguales (en $x, y, z$ ). Aquí se produce la principal crítica de J. BENTHAM.

$\mathrm{CH}$. PERELMAN intenta conjugar ambos conceptos, señalando que, desde un punto de vista formal la justicia consiste en "tratar igual a los seres pertenecientes a la misma categoría", lo que debe ir unido a una regla o criterios materiales para saber cuando dos seres pertenecen a la misma categoría, considerando que han existido seis reglas materiales de justicia: a) a cada uno lo mismo; b) a cada uno según lo atribuido por la ley; c) a cada uno según su rango; d) a cada uno según sus méritos o su 
capacidad; e) a cada uno según su trabajo; f) a cada uno según sus necesidades.

En la práctica, se ha acudido a la mayor parte de los criterios formulados, dando mayor o menor importancia a cada uno de ellos atendiendo a la ideología dominante. En lo que se refiere al último aspecto de la división realizada por $\mathrm{CH}$. PERELMAN (a cada uno según sus necesidades), el problema que se ha planteado es qué se entiende por necesidad. La Escuela de Budapest y especialmente A. HELLER se ha referido a las necesidades radicales, como necesidades cualitativas que han de ser reconocidas y satisfechas por todos los hombres, pero no queda claro este concepto ya que este autor señala que todas las necesidades deben ser satisfechas salvo aquéllas cuya satisfacción presuponga que se convierta al hombre en un simple medio para los demás. En este sentido, cabe destacar la aportación realizada por A. E. PÉREZ LUÑO.

Se distingue también entre igualdad en el proceso de distribución e igualdad en el resultado de la distribución. La igualdad en los procesos de elección de representantes políticos (art. 23 C.E) caracteriza la democracia representativa; mientras que la igualdad como reparto igual del poder político, propio de la democracia directa o participativa (art. 23.1 C.E.), constituyen dos esferas diferentes de igualdad.

La igualdad ante la ley, expresada en el art. 14 de la C.E. significa que las normas deben aplicarse del mismo modo ante casos iguales. La igualdad en la ley, a la que se refiere el art. 9.2 de la $C E$, significa la exigencia de que la ley contribuya a hacer a todos efectivamente iguales.

En los derechos humanos subyace la tensión entre el Hombre y el Estado, ya que tienen el aspecto de la consideración del hombre, individualmente considerado, pero también desde la perspectiva social (el hombre es un ser social por su propia naturaleza). En cuanto a la primera dimensión, el hombre, en cuanto persona, constituye un valor absoluto. No obstante, no hay que descuidar el aspecto social del hombre, si bien la sociedad, el Estado, constituye un medio y no un fin para el hombre.

\subsection{El principio de dignidad}

Los valores sobre los que se asientan los derechos humanos son la dignidad, la libertad y la igualdad. La dignidad es valor fundamental del aspecto individual del hombre como persona, y en el que parecen asentarse la mayor parte de las declaraciones. La dignidad del hombre es el fundamento de su autodeterminación, ya que el hombre es un ser libre, en base a su razón humana y no se encuentra predeterminado por la naturaleza indefectiblemente.

\subsection{Justicia y Bien Común}

Otro aspecto del ser humano es su dimensión social. Desde esta perspectiva los valores fundamentales son la Justicia y el Bien común. La justicia, como valor jurídico, es el fin al que el Derecho tiende y armoniza los fines individuales y los sociales. 
En cuanto al bien común, ha sido objeto de tratamiento por ARISTÓTELES (Politica) y TOMÁS DE AQUINO y toda la tradición aristotélico-tomista posterior con el fin de fundamentar instituciones y servir de base al ordenamiento jurídico.

El bien común no es individual, sino social, aunque facilita la obtención de bienes individuales. Tampoco es el bien de todos o suma de bienes particulares, ya que la sociedad tiene una función propia que cumplir y es supra-individual; está por encima del tiempo y del espacio. Constituye el bien de la sociedad comunitariamente considerada, en su unidad compleja. Tiene un contenido pluralista, en cuanto existen múltiples instituciones sociales con sus propios fines, que han de conjugarse, incluso, con el bien común de la humanidad. Ambos valores sociales -justicia y bien común- se encuentran íntimamente relacionados, especialmente la justicia distributiva y la justicia general o legal, ya que los bienes sociales son objeto de disfrute proporcional.

\section{CARACTERES DE LOS DERECHOS HUMANOS}

Los tres rasgos fundamentales que la tradición doctrinal les adjudica a estos derechos son:

\subsection{Universalidad}

A través de este principio se considera que todas las personas tienen derecho a disfrutar del contenido de los derechos humanos. Simplemente por el hecho de ser persona, como requisito mínimo, es suficiente para reconocer su extensión universal, al margen de cualquier otra circunstancia.

Cuestión distinta es la justificación del ámbito de la universalidad, ya que se han hecho una serie de preguntas: ¿son universalizables todos los derechos humanos?, ¿cuántos y cuáles son realmente derechos humanos?, ¿se incluyen absolutamente todos los seres humanos a pesar de sus diferencias?, ¿y los restantes seres sensibles, son también portadores de este tipo de derechos?

La primera consecuencia que de ello se deriva es que la universalidad de los derechos humanos nos obliga a extraerlos del sistema jurídico positivo y pasar a considerarlos como derechos morales porque, en efecto, no estamos hablando de unos derechos que los ciudadanos de un país tengan en función de su sistema jurídico y que les falte a los ciudadanos de otro país, precisamente en función de este sistema jurídico.

Existe una incompatibilidad conceptual al afirmar simultáneamente que los derechos humanos son universales y que son un producto de un ordenamiento jurídico positivo porque la condición de sujeto de un sistema jurídico excluye esta noción de universalidad a no ser que se pretenda argumentar la existencia de un sistema jurídico positivo cuyas normas fueran universales y resulta evidente que esta posibilidad hoy en día y por ahora no deja de ser una condición utópica, es por esto por lo que se ha considerado más apropiado situar a los derechos humanos en el ámbito de la ética considerándolos más como derechos morales y no como derechos legales. Los 
derechos humanos no pertenecen a un ordenamiento jurídico, no son derechos humanos por pertenecer a éste sino que son unos derechos anteriores a todos los ordenamientos jurídicos, estos nacen en función de la protección de estos derechos.

M. KRIELE es defensor de la universalidad de los derechos humanos pero realiza un estudio de los críticos de la universalidad. Interesa hacer mención a la ponencia de este autor que presenta al Congreso Mundial de filosofía jurídica y social en Göttingen en 1991. Esta ponencia lleva por título La universalidad de los derechos del hombre, y en ella dice que con la expresión "derechos del hombre" estamos identificando a todos aquellos derechos que le corresponden al hombre en virtud de su condición de hombre, por tanto no se pueden excluir de la titularidad de estos derechos a ningún hombre ni a ningún grupo de hombres. Estará implícito en el concepto de derechos del hombre que solamente se pueden considerar estos como universales, de tal manera que de no tener esa condición de universal, carecería de todo sentido hablar de los derechos del hombre. Han existido culturas en el pasado y hay todavía sociedades del presente que entienden que los derechos del hombre sólo valen subordinados a determinados presupuestos, por ejemplo, los derechos del hombre tendrían sentido únicamente en determinados ámbitos culturales en los cuales está arraigada la metafísica occidental o bien la teología judeocristiana o tan solo en una sociedad individualista burguesa. M. KRIELE considera, sin embargo, que en estos casos no tendría sentido hablar de los derechos del hombre y que sería más correcto referirse a los derechos de los europeos, derechos de los americanos o derechos de las democracias occidentales. Señala que la existencia de los derechos del hombre, teniendo en cuenta que son para un grupo reducido, serían una mera apariencia, una ilusión causada por nuestra incapacidad para comprender otras estructuras mentales o tradiciones culturales que rigen en diversos lugares del mundo y que relativizarían nuestra imagen del derecho. Quienes así piensan, entienden que esa imagen del derecho nos remitiría a una universalización ligera, que es la imagen que se habría formado en Europa y en América en una etapa en la cual se pretendía imponer nuestra cultura al resto del mundo (el colonialismo).

El concepto moderno de derechos del hombre fue elaborado, según hemos referido anteriormente, por la ilustración y el iluminismo político del siglo XVIII, la idea de unos derechos universales de la persona se desarrolló en el ámbito del derecho natural racionalista. Se consolidó en el ámbito de la teoría del deber ser y no en la teoría del ser del derecho positivo, que es una teoría separada del derecho natural racionalista.

Cuando en la segunda mitad del siglo XVIII se impone en el continente europeo la idea de los derechos del hombre, dominaban de forma casi general los estados absolutos, por lo tanto era una contradicción entre lo que realmente era y lo que debía ser. Se daba incluso el caso de que los enciclopedistas aconsejaban a déspotas ilustrados. Esta doctrina de la Ilustración vio precisamente en los derechos naturales y los utilizó como una bandera política frente al positivismo de los Estados Absolutos. Estos autores exigían que los derechos del hombre pudieran ser reconocidos por el derecho positivo y por lo tanto pasar a convertirse en derechos fundamentales, lo que quiere decir, derechos vigentes y reclamables en juicio. 
Si se aceptan estos presupuestos no es posible afirmar o creer en la relatividad de los derechos del hombre que se producirían a partir de las técnicas o diferencias de reconocimiento en los derechos fundamentales de los distintos países. Si es cierto que los derechos del hombre todavía no poseen en la mayor parte de los Estados una urgencia positiva, es precisamente por eso por lo que la idea iusnaturalista de la universalidad de los derechos del hombre continuaría teniendo vigencia. En atención a ello, la idea de los derechos del hombre continuará teniendo fuerza moral y fuerza política, que será reformista en algunos casos o revolucionaria en otros, hasta que los derechos del hombre hayan sido reconocidos en el derecho positivo de todos los Estados Soberanos.

Los críticos de la universalidad de los Derechos del hombre invocan entre otras explicaciones la condición relativa de estos derechos y lo hacen en base a dos tipos de argumentos: históricos o geográficos, o sea relativismo histórico o regional. Por lo que respecta al relativismo histórico, S. P. HUNTINGTON considera que los Derechos del hombre en el pasado no existían. La esclavitud llegó a ser considerada o justificada por ARISTÓTELES. La tortura hasta hace muy poco tiempo era un sistema legal dirigido a obtener confesiones judiciales en las normas de procedimiento. Las penas infamantes, consistentes en despojar de prestigio eran practicadas con carácter general hasta no hace mucho. Las persecuciones religiosas estaban a la orden del día así como también los métodos procesales primitivos, el trabajo de menores y la ausencia de derechos en la mujer. Todo esto ocurría sin que se opusiera resistencia o sin que se levantaran especiales protestas en nombre de los Derechos humanos, además alguno de estos fenómenos llegaron a ser considerados legítimos en el pasado y fueron precisamente los iluministas del siglo XVIII los que ofrecieron todo un programa de reforma que tenía como objetivo, denunciar como injusta esta situación y reclamaron que se iniciara un proceso de transformación del Derecho con alcance para toda la humanidad.

Los críticos de la universalidad de los Derechos humanos en ocasiones muestran las distintas sensibilidades y las distintas actitudes culturales con respecto a los Derechos humanos. Quienes adoptan una postura relativista regional o geográfica ponen en evidencia, no sólo que los Derechos humanos fueran desconocidos de hecho en muchos países sino que además, los Derechos del hombre expresarían o tendrían como objetivo una concepción del Derecho y de los valores no universales y que estarían vinculados a un tiempo y espacio muy concreto, que sería la cultura occidental posterior a la ilustración y a las revoluciones burguesas de la segunda mitad del siglo XVIII (Revolución Francesa y Revolución Americana).

\subsection{Carácter absoluto}

Significa que nadie puede reducir estos derechos justificadamente. Esta idea hace referencia directa a lo que habitualmente se llama importancia de los Derechos humanos. Lo que late tras esta condición de Derechos Absolutos o Derechos importantes es la idea de fuerza, o sea de exigencia moral fuerte. Con ello se hace referencia al carácter urgente de los derechos humanos. 
Esa fuerza deriva necesariamente del bien, de la situación o estado de cosas que se trata de proteger con ese derecho. Esta fuerza característica procede de la idea de que estos derechos son la expresión de bienes de particular relevancia para los seres humanos.

En este sentido y siguiendo la misma línea argumental de prácticamente todos los autores, S. BENN considera que los Derechos humanos son afirmaciones de interés o necesidades básicas es decir, que se trata de intereses o de necesidades cuya satisfacción se considera un bien caracterizado de una forma tan rotunda como básica.

En este sentido, los Derechos Humanos en cuanto derechos absolutos representan las condiciones mínimas bajo las cuales los seres humanos pueden prosperar debiendo ser asegurados, en caso necesario, incluso con la fuerza.

Desde los orígenes mismos de la teoría de los Derechos Naturales en el siglo XVII, se puede apreciar como una constante una cierta aceptación de la utilización de la violencia cuando se trata de defender los Derechos Humanos y esta utilización estaría moralmente aceptada o justificada. Así por ejemplo, H. GROCIO admitía la existencia en el Estado de Naturaleza de un derecho natural a castigar, que justificaba el empleo de la fuerza para defender los derechos naturales.

Esta misma concepción aparece expresada por el iniciador de la Ilustración inglesa. J. LOCKE, quien justifica plenamente la utilización de la fuerza como salvaguardia de los Derechos Naturales. También T. HOBBES, mantiene esta misma tesis. I. KANT se ocupa del tema en dos de sus obras: Fundamentos de la metafísica de la costumbre, de 1785 y Sobre la paz perpetua, de 1795, considerando la presencia de la fuerza como algo que acompaña inevitablemente al Derecho. Tiene su fundamento precisamente en la protección de estos derechos innatos, es decir, para I. KANT la coercibilidad es una nota esencial del Derecho y sobre todo se produce como garantía de los derechos innatos. Esta coercibilidad del derecho no solamente es lícita sino que además se considera como moralmente necesaria porque sin la coercibilidad la fuerza arbitraria de unos podría impedir a otros la actuación del uso de su libertad. El imperativo jurídico supremo del autor consiste en: "Obra de tal manera que el libre uso de tu arbitrio pueda coexistir con la libertad de cada cual según una ley universal de libertad". La coercibilidad se justificará sólo en la medida en que se trata de evitar que alguien abuse de su libertad en detrimento de la libertad de terceros.

Para I. KANT es necesario distinguir entre derechos innatos y los que él denomina derechos adquiridos. Los derechos innatos son aquellos que corresponden a todo ser humano por su propia naturaleza, sin que sea preciso su reconocimiento jurídico y los adquiridos son los de creación jurídica. De acuerdo con este autor, en última instancia, el derecho originario o innato que corresponde a todo hombre en virtud de su humanidad es precisamente la libertad. La libertad entendida aquí como independencia de unos con respecto al arbitrio restrictivo de otros en cuanto que pueda coexistir con la libertad de los demás, es decir, que este derecho a la libertad conlleva en sí todos los demás derechos y fundamentalmente, o en primer término, el 
derecho a la igualdad, por virtud del cual, no podemos obligar a otros a más que lo que ellos pueden obligarnos a nosotros.

La tradición moderna de los Derechos del Hombre (J. LOCKE y H. GROCIO) confirma la idea según la cual estos tienen la consideración de bienes personales cuya protección mediante la violencia esta moralmente justificada y dicen algunos autores que es quizá precisamente aquí donde radica el origen de su fuerza y también su condición de derechos absolutos. Para estos autores de la escuela moderna, en el Estado de Naturaleza los individuos podían utilizar la violencia privada para la protección de sus derechos, pero, una vez constituida la sociedad tras el pacto social, la violencia resulta monopolizada y publificada/garantizada.

Algunos autores que estudian este tema han interpretado, de forma errónea, que solamente puede hablarse de Derechos Humanos cuando contamos con un dispositivo estatal legal de protección institucionalizada de estos derechos. Pero lo que nos quieren decir estos primeros teóricos es que lo que justifica este dispositivo estatal legal, es precisamente la existencia de Derechos Humanos.

A. GEWIRTH, profesor de la universidad de Chicago, publicó en 1982 un trabajo titulado ¿Existen Derechos Absolutos?, en el que sostiene que un derecho es considerado como absoluto cuando no puede ser desplazado en ninguna circunstancia, de tal forma, que nunca podrá ser infringido justificadamente y siempre ha de ser satisfecho sin ninguna excepción.

A partir de la teoría ética de J. RAWLS, que surge como una línea de pensamiento a favor de los Derechos Humanos, la idea de los Derechos Humanos como absolutos se ha caracterizado como la existencia de derechos no susceptibles de negociación.

R. DWORKIN, en su obra Los derechos en serio, sostiene que si alguien tiene un derecho absoluto a algo, es incorrecto que el gobierno se lo deniegue, incluso si fuera de interés general el hacerlo. Detrás de esta tesis está la idea de la no negociabilidad de los derechos básicos y en el supuesto de que se de un conflicto entre un derecho básico y decisiones políticas adoptadas o tomadas por una mayoría impecablemente democrática, decimos y afirmamos que los derechos básicos desplazarán al resto de las consideraciones. Se dice que los derechos básicos son absolutos porque en el caso de conflicto de estos derechos básicos con consideraciones morales colectivas o bien con demandas individuales que no sean constitutivas de derechos básicos, logran imponerse a los dos tipos de demandas desplazándolas.

Los derechos son concebidos como absolutos al ser considerados como los requerimientos morales más fuertes que se dan en el discurso moral y que por lo tanto sólo podrán ser desplazados por requerimientos morales que sean equivalentes y que están en conflicto con ellos, es decir, con otros derechos humanos.

La Declaración Universal de las Naciones Unidas o la Convención Europea de los Derechos Humanos no toman en consideración realmente a los derechos humanos 
como derechos absolutos porque los condicionan, acotan y limitan. Así por ejemplo, la Declaración de Derechos Humanos de la O. N. U., en su artículo 24 párrafo segundo, somete el resto del articulado a unas limitaciones derivadas de la justa exigencia de la moral, del orden público y del bienestar general de la sociedad.

La Convención Europea, establece grandes trabas a los derechos humanos como el derecho a la libertad de expresión que tiene como límites la seguridad nacional y la protección de la moral. Existen también gran parte de constituciones y declaraciones de derechos nacionales que incluyen en su articulado cláusulas limitativas y que no se ajustan a esta concepción de los derechos humanos como derechos absolutos. Hay autores que señalan que esto es debido a que los derechos humanos son muy amplios.

Algunos autores han considerado que los derechos humanos están unidos a la idea de derecho absoluto que refuerza la idea de universalidad. Los derechos humanos serían los que tienen todos los miembros del ámbito de universalidad porque nadie puede rehusar el reconocimiento de estos derechos y de las exigencias de dignidad basadas en ellos. Por esta vía se llegó a la crítica realizada por J. BENTHAM tachándolos de "sin sentido en zancos".

\subsection{Carácter inalienable}

Es muy frecuente que esta condición o propiedad que se predica de los derechos humanos se confunda con las dos anteriores, de tal manera que algunos estudios del tema identifican la inalienabilidad con el carácter absoluto o con la universalidad. Al hablar de la inalienabilidad adoptamos la perspectiva o punto de vista de aquellas personas que son titulares del derecho, más que el del que lo ha de respetar. Un derecho es inalienable cuando su titular no puede perderlo, con independencia de lo que haga o de cómo le traten los demás, incluso si éstos están justificados para no concederle lo que demanda en ejercicio de su derecho. Los derechos como inalienables no se pueden rechazar ni siquiera de forma voluntaria; en este sentido, por ejemplo nadie podría ser esclavo de forma voluntaria. En definitiva, los derechos inalienables (a diferencia de los absolutos que son los que no pueden ser justificadamente restringidos) son aquellos que no se pueden perder.

En los derechos inalienables se produciría una relación entre éstos y sus presuntos titulares que no se pueden romper. Estas conexiones se han visto: a) como consecuencia de teorías psicológicas, en la que se entiende que las leyes de la psicología establecen la renuncia de algunos titulares a las opciones garantizadas por los derechos inalienables. Esta es la explicación que se hace de la defensa que realiza T. HOBBES cuando señala que los derechos inalienables no pueden negociarse, del mismo modo que la postura que adopta S. M. BROWN (Jr.) con respecto a los derechos inalienables (Inalienable Rights); b) como conceptos de la persona, por lo que estas opciones son condiciones necesarias para la personalidad 0 un postulado similar. Este es el tratamiento que lleva a cabo J. LOCKE, cuando señala que una persona tiene estos derechos porque Dios la ha creado así (Ensayo sobre el gobierno civil), así como H. B. MORRIS y R. NOZICK, aunque los dos últimos no ligan esta 
noción a creencias religiosas; c) como ideales sociales, ya que no podría alcanzarse un ideal social a menos que las personas disfruten de ciertas opciones; esta posición se vincula a T. H. GREEN, quien explica los derechos inalienables como derivados de un ideal social, así como T. BLACKSTONE y M. GOLDING.

Puesto que un derecho puede perderse mediante renuncia, transferencia, pérdida legal, los derechos inalienables no podrían perderse de ninguna de estas formas. Las renuncias pueden serlo de hecho, que dejan al renunciante del derecho igual de libre que a los demás frente al objeto del derecho renunciado. $Y$ renuncias conscientes, cuando lo hacen por convicciones morales, en cuyo caso asumen la obligación de autocontrolarse con respecto al objeto del derecho. El concepto de "supererogación" explica el concepto de un derecho que no es renunciable por razones de conciencia a causa del especial valor de su objeto. Los derechos inalienables serían aquellos que tienen unos objetos cuyo sacrificio altruista sería supererogatorio o inapropiado y, en cualquier caso, no podría ser obligatorio. Supone que una persona sacrifica algo valioso para beneficiar a otro a pesar de que no tiene el deber de hacerlo.

D. MEYERS, considera que son cuatro los derechos inalienables y deben reunir dos condiciones:

1. Que su objeto nunca sea modificado obligatoriamente, aunque de forma altruista pueda ser sacrificado supererogatoriamente.

2. Que estos derechos protejan un bien del que precisan los individuos para funcionar como agentes morales, lo que quiere decir que la elección y el seguimiento de un código de conducta es algo que toma en consideración los intereses de los demás.

Dice esta autora que son cuatro los derechos que reúnen estas condiciones:

a) Derecho a la vida, derecho a no ser privado de ella. Prohíbe que otras personas quiten la vida al poseedor de ese derecho y a su vez le permiten que este pueda defenderse de los ataques de los cuales puede ser objeto. Una persona es un agente moral -sujeto a unas normas o criterios- y es por ello por lo que el derecho a la vida protege algo esencial para la actuación moral. Las personas no están obligadas a arriesgar sus vidas por razones altruistas a menos que hayan prestado su conformidad para comprometerse en una conducta que de otro modo sería supererogatoria.

b) Derecho a la libertad personal, entendiendo este derecho como el derecho a no ser forzado a ejecutar la voluntad de otras personas. Este derecho se propone proteger a sus titulares del sometimiento a la voluntad de terceros y tiene conexión directa con la acción moral porque no considera responsables de sus acciones cuando son obligadas de una forma insuperable por otras personas. Las violaciones de este derecho suponen la existencia de una orden acompañada de una amenaza de daño. Daños que los 
demás no pueden infringir al poseedor de tal derecho para obtener su sumisión. Las restricciones sobre la libertad personal siempre dejan una posibilidad de opción a la persona, y nunca son equivalentes a la acción coactiva. Sólo una denegación ejecutiva de la libertad personal puede acabar con la actuación moral porque este tipo de denegación no se distingue de la coacción. La libertad personal debe estar constreñida por los derechos inalienables de los demás.

c) Derecho a un buen trato o derecho a no sufrir gratuitamente. Este es un derecho muy distinto a la vida o a la libertad (entendiéndola como libertad personal). En primer lugar, cuando hay una violación clara del derecho a la vida, destruye a la persona y con ello la posibilidad de que se actúe como un agente moral. En segundo término, también cuando se viola el derecho de una persona a la libertad, se está impidiendo ya sea temporal o permanentemente su acción moral. Si a pesar de esto, se considera el derecho a un buen trato como un derecho inalienable es por la relación instrumental que tiene con los derechos mencionados anteriormente, porque si sometemos a una persona a un gran dolor, podemos matarla o controlarla. El derecho a un trato justo proporciona un modo de protección de la acción moral y equivale al derecho a no sufrir un dolor gratuito. Este derecho equivale a que esa persona no podrá ser objeto de tortura 0 de violencia. También se puede incluir el derecho a medicamentos o a ser curado de una enfermedad.

d) Derecho a la satisfacción de las necesidades básicas. Derecho a disponer de una alimentación básica, agua, vestidos y vivienda y al tratamiento y cuidado médico que son necesarios para sobrevivir. Este derecho la doctrina anglosajona lo denomina derecho paraguas en el sentido que es un derecho que cubre o ampara un conjunto de derechos subsidiarios.

Para que estos derechos puedan considerarse como inalienables deben:

1) Tratarse de derechos que previenen ciertas formas de privación que pueden causar un gran dolor o sufrimiento o incluso la muerte de la víctima, estas condiciones básicas a las cuales se deben satisfacer han de ser críticas.

2) Tienen que tratarse de derechos que cualquier persona necesite en algún momento, es decir, que se trata como necesidad de cosas consideradas como necesidades básicas universalmente.

3) Los objetos de estos derechos de este tipo son cosas que habitualmente la gente puede procurarse por sí misma, pero que puede no ser así; las 
necesidades básicas son personales. Las necesidades básicas se satisfacen normalmente y de no hacerlo dejan a los individuos en situaciones extremas.

Diferencia esta autora un código personal de un sistema moral en que el primero no es universalizable. Ni todo lo que una persona debe hacer es exigido por la moral ni lo que una persona tiene que dejar de hacer es inmoral. Que un código personal pueda prescribir sacrificios altruistas no significa que lo puedan hacer los sistemas morales. Los códigos personales deben operar en los lugares que dejan libres los sistemas morales.

Algunos autores de la Edad Moderna, destacando a H. GROCIO dicen, cuando analizan el tránsito del Estado de Naturaleza a la Sociedad Civil, que los individuos entran en dicha sociedad, renunciando a varios derechos, como, por ejemplo, el derecho natural de autodefensa, y lo hacen entendiendo que en la Sociedad Civil la violencia sólo la puede ejercer legítimamente el Estado.

Después de H. GROCIO, los tratadistas del Derecho Natural se plantearon el problema pretendiendo describir una situación en la cual no existe propiamente una autoridad política establecida. El papel que cumplía la idea del Estado de Naturaleza consistía en justificar la existencia del Estado, o bien en negar su necesidad, o bien comparar la condición más feliz del hombre civilizado frente al hombre primitivo, o bien para invertir el sentido de esta comparación. Ahora bien, si consideramos que este tránsito del Estado de Naturaleza a la Sociedad Civil se considera un acto voluntario y libre de los individuos caben dos formas o dos modos de realizar este tránsito:

1. Renunciando a todos los derechos naturales.

2. Renunciando sólo a alguno de estos derechos.

La disyuntiva es importante porque a partir de aquí arrancan dos teorías de los derechos de significado contrapuesto, que son la teoría conservadora y absolutista y la teoría progresista y liberal. La primera dará paso a un Estado Omnipotente que ejerce sus derechos sobre los ciudadanos, los individuos a los cuales no les reconoce derechos frente a él. La segunda se manifiesta a favor de un Estado con un poder limitado por unos derechos morales que son anteriores a él, reconoce unos derechos naturales.

\section{REFERENCIAS}

Aristóteles (384-322 a. C): Ética nicomaquea. Madrid: Gredos.

Atienza, M. (1991): Introducción al Derecho. Barcelona: Barcanova, S.A.

Benn, S. y Peters, R. (1959): Social principles and the democratic State. Londres: Allen and Unwin.

Bentham, J. (1962): Analchical Fallacies: being and examination of the Declarations of Rightsissued during the French Revolution. Nueva York: De Russell \& Russell. 
Berlin, I. (1974): Dos conceptos de libertad, en A. Quinton. Madrid: Filosofía política.

Cerroni, U. (1972): La libertad de los modernos. Barcelona: Martínez Roca

Dworkin, R. (1984): Los derechos en serio. Barcelona: Ariel.

Hobbes, T. (2009): Leviatán, Madrid: Alianza.

Perelman, Ch. (1964): De la justicia. México: UNAM.

Pérez Luño A. E. (1984): Derechos humanos, Estado de Derecho y Constitución. Madrid: Tecnos.

\section{Cristina Fuertes-Planas Aleix}

Licenciada en Derecho por la Universidad Complutense de Madrid. Doctora en Derecho y profesora de Derecho Canónico y Eclesiástico en el C.U. Cardenal Cisneros desde 1986 hasta 2006. Profesora de Derecho en la Facultad de Ciencias de la Información (UCM), Sección Departamental de Filosofía del derecho desde 1992. Secretaria de la Sección Departamental de Filosofía del Derecho en la Facultad de Ciencias de la Información (UCM) desde 1992. 